\title{
Assessing the Effects of a Health Belief Model-Based Educational Program on Knowledge Attitudes and Practice (KAP) among Patients with Pemphigus vulgaris
}

\author{
Roya Sadeghi' ${ }^{1}$, Azar Tol ${ }^{1}$, Masoud Baikpour ${ }^{2}$, Azita Moradi' ${ }^{1}$, Mostafa Hossaini ${ }^{3 *}$ \\ ${ }^{1}$ Deptartment of Education and promotion, School of Public Health, Tehran University of Medical Sciences, \\ Tehran, Iran \\ ${ }^{2}$ School of Medicine, Tehran University of Medical Sciences, Tehran, Iran \\ ${ }^{3}$ Department of Epidemiology and Biostatistics, School of Public Health, Tehran University of Medical Sciences, \\ Tehran, Iran

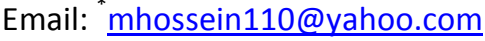

Received 9 June 2014; revised 1 July 2014; accepted 2 August 2014

Copyright @ 2014 by authors and Scientific Research Publishing Inc.

This work is licensed under the Creative Commons Attribution International License (CC BY).

http://creativecommons.org/licenses/by/4.0/

\section{cc) (7) Open Access}

\begin{abstract}
Introduction: This study aimed to evaluate the effects of an educational program based on Health Belief Model on knowledge, attitudes and practice (KAP) in patients with Pemphigus vulgaris (PV) referred to Razi Hospital in Iran. Materials and Methods: This quasi-experimental study was conducted on 88 patients in 2013-2014. Subjects were divided into two intervention and control groups using block randomization. In addition to their usual care for both groups, the intervention group sat through a six-month self-care educational program in a specialized outpatient clinic. A self-designed questionnaire was used to gather information about demographic characteristics, PV related variables, and KAP-related questions. Data were analyzed using SPSS Software. p value of less than 0.05 was set as statistically significant. Results: mean scores of KAP increased significantly after intervention compared to control groups when adjusted for baseline differences of these scores and house ownership and employment status differences in two groups. Conclusion: study results show the effectiveness of an HBM based educational program on KAP in PV patients that can lead to adoption of self care behaviors and help them gain self efficacy in controlling their disease and assisting their treatment process, counting as a tertiary preventive measure.
\end{abstract}

\section{Keywords}

KAP, HBM, Intervention, Pemphigus vulgaris

\footnotetext{
${ }^{*}$ Corresponding author.
}

How to cite this paper: Sadeghi, R., et al. (2014) Assessing the Effects of a Health Belief Model-Based Educational Program on Knowledge Attitudes and Practice (KAP) among Patients with Pemphigus vulgaris. Journal of Cosmetics, Dermatological Sciences and Applications, 4, 244-249. http://dx.doi.org/10.4236/jcdsa.2014.44033 


\section{Introduction}

Categorized as one of the immunobullous diseases, pemphigus is characterized by widespread blistering and erosions affecting the skin and mucous membranes [1]. Of the six recognized variants of Pemphigus, Pemphigus vulgaris (PV) has the greatest prevalence [2]. The incidence of this disease varies from one to five cases per 1 million population per year but it is increased in patients of Ashkenazi Jewish descent and those of some Eastern countries including India, Malaysia, China, and Japan [1] [2]. As well as other parts of the world, PV is the most prevalent variant in Iran with prevalence rates of $0.64-1.5 / 10^{5}$ population/year, reported by some sporadic researches [3]-[5]. In a study conducted by Pemphigus Research Unit in Razi Hospital, a dermatology referral center in Tehran, Iran, its prevalence was reported to be approximately 1 per $10^{5}$ population per year [6]. Studies have shown differences in onset, occurrence and prognosis of the disease regarding age and gender in PV patients. Current evidence shows an earlier onset of the disease in Iran compared to other parts of the world [3]-[5]. As for the gender females are reported to be at greater risks of PV disease [3]-[7], strong evidence suggests that according to inadequate preventive measures for chronic diseases such as PV in routine clinical practice, patients could benefit from substitute measures such as self-care behaviour programs to limit the risk of recurrence. Adopting self care behaviours by the patients suffering from chronic conditions is very important since such diseases are basically managed by the patients themselves. Regarding the late onset of PV in the fourth decade of life along with other chronic diseases, the necessity of self-care behaviour is more prominent [8]. Therefore, the importance of employing self-care behaviours is emphasized by the guidelines of PV management, as well as other points such as the significance of medical regimen for symptomatic treatments, dealing with side effects of the medications and adherence to suggested dietary changes such as avoiding nuts and spicy foods containing garlic, onion or leek. Regarding the bulbous nature of PV, paying special attention to wound healing process, prevention and treatment of infection is of utmost importance [9]. Psychological stress is another important subject that should be considered in the management of this disease [10]. Health professionals are challenged to publicize the best of what is known in new conditions. Given a new condition or problem, health professionals are obligated to apply the best of what is known in their practice. The topic of implementing Health Behavior and Health Education in clinical practice is a dynamic argument among researchers trying to yield effective health education [11]. Health Belief Model (HBM), the theoretical framework applied in this study, is used to assess the patients' motivation to adapt to a health related behavior [11]. The impact of educational programs on self-care behaviour modifications in some chronic diseases is confirmed in existing literature [12]-[14]. This study aimed to evaluate the impact of an HBM based interventional program on the knowledge, attitudes and practice of the patients with pemphigus Vulgaris, referred to Razi Hospital in Tehran, Iran.

\section{Patients and Methods}

Approved by the Educational Deputy of Tehran University of Medical Sciences, the present study was a randomized educational intervention trial carried out in 2013-2014. The inclusion criteria for the study population included confirmed PV diagnosis through skin biopsy, being diagnosed with the disease for at least 6 months and tendency to participate in the study. The exclusion criteria were being unable to attend the educational program or missing one fourth of the planned sessions. 88 eligible patients with PV participated as intervention or control groups. The objectives of the study were clearly explained to them in their first visit to the dermatology center. Patients were invited to join group meetings in the center where they were asked queries about the study, gave verbal informed consent, provided baseline data and were divided randomly to two groups of intervention and control. The random allocation sort was performed using randomization block of size four. The subjects in intervention group were assigned to participate in a 6-month educational program including group discussions and problem solving strategies based on Health Belief Model to adopt self-care behaviors. The control group did not receive any further intervention more than that of the routine treatment plan of the center. At the start of study and three months after the last session of the self-care educational program, data were collected from patients in both groups.

The self-designed questionnaire comprised of two sections: First, demographic characteristics and PV related variables (14 items) including age, gender, level of education, family income, occupation, smoking, the time of disease incidence and recurrence, history of surgery and disease duration; Second, KAP including 22 items assessing knowledge, 10 items assessing attitudes based on 5-point Likert scale (completely disagree $=1$ to completely agree $=5$ ) and 10 items for practice whose score was based on a 4 -point Likert scale (not at all $=1$ to 
always $=4$ ), ranging from 10 to 40 . Higher score means higher tendency to adopt healthy practices. Cronbach's Alpha was computed for knowledge, attitude and practice and were $0.93,0.93$ and 0.91 , respectively. The PV self-care educational program was instructed by one of the researchers aware of the health education models.

The educational program comprised of six group discussion and problem solving sessions focusing on selfcare measures for the disease. The patient and the educator assessed the basic information in the initial session, to classify the patient's problems in order to find areas demanding more enforcement, and also to set goals. On the other five sessions materials based on HBM constructs were covered [11]. The program lasted 2 months. After intervention stage and filling the related questionnaire, patients had three months to get prepared for changing primary behaviors and trying to adopt self-care behaviors to promote their lifestyles. After three months, patients filled out the questionnaire again. This program aimed to help patients solve their self-care issues, to show the significance of self-care behaviors, to set up steps to reach the goals and also to enhance general knowledge about PV self-care measures. It should be mentioned that in this trial we did not change the medical treatment of the patients. Educational topics were set by the HBM constructs according to each session. Patients in both groups filled out the questionnaires based on study timetable. Data analysis was performed using SPSS software version 20 via descriptive and inferential statistical tests. Socio-demographic and disease related variables were compared at baseline between the two groups. Using independent samples T-test and Chi Square test, we compared the means and proportions in the study groups. Ordinal variables were compared by Mann-Whitney U test and ANCOVA was utilized to compare the mean score of KAP components after intervention, adjusting for possible differences in their baseline values and those demographic characteristics with different distributions compared to the study groups. A p value of less than 0.05 was considered as statistically significant.

\section{Results}

Demographic characteristics of the patients according to intervention are shown in Table 1 . The mean age of patients in intervention and control group were $52.6 \pm 11.0$ and $56.5 \pm 8.8$ years, respectively $(p=0.06)$. In randomization of the patients, 28 female and 16 male were assigned to intervention and 34 female and 10 male to control group $(\mathrm{p}=0.16)$. In intervention group, $8(18.2 \%)$ patients were single and $36(81.2 \%)$ married. In control group, these were $15(34.1 \%)$ and $29(65.9 \%)$, respectively $(\mathrm{p}=0.09)$. Further analysis showed that the distribution education level, PV duration, history of chronic disease and other skin disease in two study group was not significantly different at the baseline $(\mathrm{p}>0.05)$ although house ownership and employment status of subjects in two group was not the same ( $\mathrm{p}<0.05)$.

The mean scores of knowledge, attitudes and practice before intervention and three months after that are shown in Table 2. The mean score of the knowledge in the intervention group was $13.1 \pm 3.6$ before the intervention which increased to $21.8 \pm 0.4$, three months after the intervention. This rise was from $9.2 \pm 2.9$ to $11.2 \pm$ 3.4 in the control group. The increase in knowledge score was significantly higher in intervention group compared with control group after adjusting for the significant difference of these scores at the baseline and also for the differences in house ownership and employment status in the two groups using ANCOVA ( $\mathrm{p}<$ $0.0001)$.

Attitude's scores showed similar trends. The mean score of intervention group rose from $40.4 \pm 5.4$ to $44.0 \pm$ 3.8 and in control group only from $34.5 \pm 4.8$ to $36.4 \pm 3.8$. Using ANCOVA and adjusting for the effect of baseline differences in attitude's scores, house ownership and employment the changes in intervention group was significant. As for the scores of the practice, it changed from $31.9 \pm 5.8$ to $37.8 \pm 2.6$ after intervention although the change in control group was from $25.9 \pm 4.6$ to $29.1 \pm 3.5$. The change in intervention group was significant after adjustment (ANCOVA; $\mathrm{p}<0.0001$ ).

\section{Discussion}

As shown scores of knowledge, attitude and practice showed promising changes after the intervention. The scores of knowledge and attitudes increased after the intervention in both groups of intervention and control, but the rise was greater in the intervention group. This indicates the positive effect of HBM based educational intervention on the patients' knowledge and attitudes regarding their disease. Namakin et al. investigated the impact of HBM based educational intervention on smoking habits of students in Birjand in 2005 [15]. Their results also showed the improvement of knowledge and attitude in these students, after this intervention. In another survey by Karimi et al. on the effect of HBM based educational intervention on adopting preventive behaviors to avoid 
Table 1. Demographic characteristics of patients according to intervention.

\begin{tabular}{|c|c|c|c|c|c|c|}
\hline \multirow{2}{*}{\multicolumn{2}{|c|}{ Demographic characteristics }} & \multicolumn{2}{|c|}{ Intervention } & \multicolumn{2}{|c|}{ Controls } & \multirow{2}{*}{$\mathrm{p}$ value } \\
\hline & & \multirow{2}{*}{$\begin{array}{l}\text { No } \\
19\end{array}$} & \multirow{2}{*}{$\begin{array}{c}\text { Percent (\%) } \\
43.2\end{array}$} & \multirow{2}{*}{$\begin{array}{l}\text { No } \\
13\end{array}$} & \multirow{2}{*}{$\begin{array}{c}\text { Percent (\%) } \\
29.5\end{array}$} & \\
\hline \multirow{5}{*}{ Age } & $<50 \mathrm{yr}$ & & & & & \multirow{4}{*}{$0.06^{*}$} \\
\hline & $50-59$ yr & 16 & 36.4 & 13 & 27.3 & \\
\hline & $60-69 \mathrm{yr}$ & 6 & 13.6 & 17 & 38.6 & \\
\hline & $\geq 70 \mathrm{yr}$ & 3 & 6.8 & 2 & 4.6 & \\
\hline & Mean $( \pm S D)$ & \multicolumn{2}{|c|}{$52.6 \pm 11.0 \mathrm{yr}$} & \multicolumn{2}{|c|}{$56.5 \pm 8.8 \mathrm{yr}$} & \\
\hline \multirow{2}{*}{ Gender } & Female & 28 & 63.6 & 24 & 72.3 & \multirow{2}{*}{$0.16^{* *}$} \\
\hline & Male & 16 & 36.4 & 10 & 22.7 & \\
\hline \multirow{2}{*}{ Marital status } & Single & 8 & 18.2 & 15 & 34.1 & \multirow{2}{*}{$0.09^{* *}$} \\
\hline & Married & 36 & 81.2 & 29 & 65.9 & \\
\hline \multirow{5}{*}{ Education } & Illiterate & 7 & 15.9 & 10 & 22.7 & \multirow{5}{*}{$0.13^{*}$} \\
\hline & Elementary & 9 & 20.4 & 18 & 40.9 & \\
\hline & Guidance & 13 & 29.6 & 3 & 6.8 & \\
\hline & High school \& diploma & 10 & 22.7 & 8 & 18.2 & \\
\hline & University & 5 & 11.4 & 5 & 11.4 & \\
\hline \multirow{3}{*}{$\begin{array}{l}\text { Employment } \\
\text { status }\end{array}$} & Employed & 15 & 34.1 & 12 & 27.3 & \multirow{3}{*}{$0.0 .2^{*}$} \\
\hline & Retired/Not-employed & 10 & 22.7 & 22 & 50.0 & \\
\hline & Housewife & 19 & 43.2 & 10 & 22.7 & \\
\hline \multirow{2}{*}{$\begin{array}{l}\text { Family history of } \\
\text { pamfigus }\end{array}$} & Yes & 3 & 6.8 & 3 & 6.8 & \multirow{2}{*}{$>0.99^{* * *}$} \\
\hline & No & 41 & 93.2 & 41 & 93.2 & \\
\hline \multirow{3}{*}{$\begin{array}{l}\text { History of other skin } \\
\text { diseases }\end{array}$} & Yes & 9 & 20.4 & 7 & 15.9 & \multirow{2}{*}{$0.58^{*}$} \\
\hline & No & 35 & 79.6 & 37 & 84.1 & \\
\hline & Owned & 32 & 72.7 & 40 & 90.9 & \multirow{3}{*}{$0.003^{* * *}$} \\
\hline \multirow[t]{4}{*}{ House ownership } & Rented & 9 & 20.5 & 0 & 0.0 & \\
\hline & Lives with a other & 3 & 6.8 & 4 & 9.1 & \\
\hline & $<2$ years & 17 & 38.6 & 8 & 18.2 & \multirow{5}{*}{$0.566^{* * * *}$} \\
\hline & 2 - 4 years & 12 & 27.3 & 10 & 22.7 & \\
\hline \multirow[t]{3}{*}{ Duration } & 5 - 10 years & 10 & 22.7 & 26 & 59.1 & \\
\hline & $>10$ years & 5 & 11.4 & 0 & 0.0 & \\
\hline & Mean $( \pm S D)$ & \multicolumn{2}{|c|}{$4.7 \pm 4.2 \mathrm{yr}$} & \multicolumn{2}{|c|}{$5.1 \pm 2.6 \mathrm{yr}$} & \\
\hline
\end{tabular}

"Mann-Whitney U test; ${ }^{* *}$ Chi squared test; ${ }^{* * * *}$ Fisher exact test; ${ }^{* * * *}$ Independent sample T-test.

Table 2. Mean $( \pm \mathrm{SD})$ of knowledge, attitude and practice before and after intervention.

\begin{tabular}{|c|c|c|c|c|c|}
\hline \multirow{2}{*}{ Components } & \multirow{2}{*}{ Group } & Before intervention & \multirow{2}{*}{$\mathrm{p}^{*}$} & After intervention & \multirow{2}{*}{$\mathrm{p}^{* *}$} \\
\hline & & Mean \pm SD & & Mean \pm SD & \\
\hline \multirow{2}{*}{ Knowledge } & Intervention & $13.1 \pm 3.6$ & \multirow{2}{*}{$<0.0001$} & $21.8 \pm 0.4$ & \multirow{2}{*}{$<0.0001$} \\
\hline & Control & $9.2 \pm 2.9$ & & $11.2 \pm 3.4$ & \\
\hline \multirow{2}{*}{ Attitude } & Intervention & $40.4 \pm 5.4$ & \multirow{2}{*}{$<0.0001$} & $44.0 \pm 3.8$ & \multirow{2}{*}{$<0.0001$} \\
\hline & Control & $34.5 \pm 4.8$ & & $36.4 \pm 3.8$ & \\
\hline \multirow{2}{*}{ Practice } & Intervention & $31.9 \pm 5.8$ & \multirow{2}{*}{$<0.0001$} & $37.8 \pm 2.6$ & \multirow{2}{*}{$<0.0001$} \\
\hline & Control & $25.9 \pm 4.6$ & & $29.1 \pm 3.5$ & \\
\hline
\end{tabular}

*Independent sample T-test at baseline; ${ }^{* *}$ ANCOVA after educational intervention adjusting for house ownership and employment status duration and house ownership.

AIDS in 2009, the same results were obtained showing the positive influence of the intervention on knowledge and attitude of the subjects [16].

The intervention in our study also caused the patients to act as they learned. The practice score increased after the intervention. The study conducted by Rahnavard et al. on the changes in smoking habits in female adoles- 
cents after an HBM based educational intervention in 2011, also revealed the positive change in practice among the subjects [17].

Shakerinejad et al. evaluated the impact of an HBM based education on KAP variables in adolescent girls about dietary calcium in 2011. They also observed statistically significant improvements in the scores of these variables [18]. In another study investigating the effect of an HBM based educational program about gastric cancer on knowledge, attitude and practice of housewives in 2012 by Alidosti et al. the results showed patterns of improved KAP variables in subjects compatible with our results [19].

Effects of an HBM based education program on screening behavior in high risk women for breast cancer were assessed in a study conducted by Hajian et al. in 2011. After the educational sessions they found elevated rates of breast self examination and clinical examination due to increased scores of knowledge, attitude and practice of the patients [20].

Mahmoodi et al. also verified these findings by inspecting the changes in KAP scores after an HBM based educational program regarding osteoporosis prevention in women with low socioeconomic status in 2011 [21]. Knowledge, attitude and practice of the pharmaceutical industry employees in Tehran concerning breast cancer and the benefits of mammography were found to be improving after an educational program based on health belief model in a study conducted by Hatefnia et al. in 2010 [22].

In another survey, Goodarzi et al. assessed the impact of distance education via mobile phone text messaging on knowledge, attitude, practice and self efficacy of patients with type 2 diabetes mellitus in Iran. Their results also showed improvements in these variables confirming the effect of education via any means on improving knowledge, attitudes and practice of the patients [23]. As can be seen, all of the studies conducted to investigate the effects of education programs based on health belief model on knowledge, attitude and practice of the subjects, yield similar results, showing improvements in these variables after educating the patients. As discussed before, many studies have evaluated the effects of educational programs on promoting self care behaviors, but no similar study have investigated this effect in PV patients, so we used a unique study population for our survey. Regarding the low prevalence of PV in Iran, finding these many patients was a great challenge for our survey, so selecting Razi hospital as our research department was one of the strengths of this study, since it is a dermatology referral center. Applying more interactive educational methods such as group discussion and problem solving that are believed to be more effective than lecturing method, was another positive aspect in our survey. Not being able to directly observe the changes in the behaviors of our patients can be mentioned as an important limitation in our study, since our data are basically subjective and given to us by the subjects, so they might differ from the reality.

\section{Conclusion}

This study shows the effectiveness of an HBM based educational program on the patients' knowledge, attitudes and practice regarding their disease. This improvement can lead to adoption of self care behaviors and help them achieve self efficacy in controlling their disease and assisting their treatment process, counting as a tertiary preventive measure. As stated above according to inadequate preventive measures for chronic diseases such as PV in routine clinical practice, self-care behaviour programs are viable substitute choices for helping these patients. The management of chronic conditions is generally based on the patient adopting self care behaviors and based on the late onset of PV in the fourth decade of life and concurrence of other chronic diseases during this period, the necessity of self-care behavior is more eminent. So as shown in this article, educational interventions can be utilized to enhance the knowledge of these patients as well as their attitudes and their practice.

\section{Acknowledgements}

The authors appreciatively thank all the personnel of Pemphigus Research Unit of Razi hospital, since this study could not have been carried out without their cooperation. Tehran University of Medical Sciences supported this survey as a part of MSPH thesis.

\section{References}

[1] Burns, T., Breathnach, S., Cox, N. and Griffiths, C. (2010) Rook’s Textbook of Dermatology, 4 Volume Set. John Wiley \& Sons, Hoboken.

[2] Joly, P. and Litrowski, N. (2011) Pemphigus Group (Vulgaris, Vegetans, Foliaceus, Herpetiformis, Brasiliensis). Clin- 
ics in Dermatology, 29, 432-436. http://dx.doi.org/10.1016/j.clindermatol.2011.01.013

[3] Salmanpour, R., Shahkar, H., Namazi, M. and Rahman-Shenas, M. (2006) Epidemiology of Pemphigus in SouthWestern Iran: A 10-Year Retrospective Study (1991-2000). International Journal of Dermatology, 45, 103-105. http://dx.doi.org/10.1111/j.1365-4632.2004.02374.X

[4] Ali, A., Ali Reza, Y. and Gita, F. (2006) Pemphigus vulgaris in Iran: Epidemiology and Clinical Profile. SKINmed: Dermatology for the Clinician, 5, 69-71. http://dx.doi.org/10.1111/j.1540-9740.2006.03756.x

[5] Javidi, Z., Meibodi, N.T. and Nahidi, Y. (2007) Epidemiology of Pemphigus in Northeast Iran: A 10-Year Retrospective Study. Indian Journal of Dermatology, 52, 188-191.

[6] Chams-Davatchi, C., Valikhani, M., Daneshpazhooh, M., Esmaili, N., Balighi, K., Hallaji, Z., et al. (2005) Pemphigus: Analysis of 1209 Cases. International Journal of Dermatology, 44, 470-476. http://dx.doi.org/10.1111/j.1365-4632.2004.02501.x

[7] Chmurova, N. and Svecova, D. (2009) Pemphigus vulgaris: A 11-Year Review. Bratisl Lek Listy, 110, 500-503.

[8] Ruocco, E., Wolf, R., Ruocco, V., Brunetti, G., Romano, F. and Lo Schiavo, A. (2013) Pemphigus: Associations and Management Guidelines: Facts and Controversies. Clinics in Dermatology, 31, 382-390. http://dx.doi.org/10.1016/j.clindermatol.2013.01.005

[9] Pemphigus (2013) http://www.pemphigus.org/index.php

[10] Picardi, A. and Abeni, D. (2001) Stressful Life Events and Skin Diseases: Disentangling Evidence from Myth. Psychotherapy and Psychosomatics, 70, 118-136. http://dx.doi.org/10.1159/000056237

[11] Glanz, K., Rimer, B.K. and Viswanath, K. (2008) Health Behavior and Health Education: Theory, Research, and Practice. John Wiley \& Sons, Hoboken.

[12] Sharifirad, G., Entezari, M.H., Kamran, A. and Azadbakht, L. (2009) The Effectiveness of Nutritional Education on the Knowledge of Diabetic Patients Using the Health Belief Model. Journal of Research in Medical Sciences: The Official Journal of Isfahan University of Medical Sciences, 14, 1-6.

[13] Sharifirad, G.R., Tol, A., Mohebi, S., Matlabi, M., Shahnazi, H. and Shahsiah, M. (2013) The Effectiveness of Nutrition Education Program Based on Health Belief Model Compared with Traditional Training. Journal of Education and Health Promotion, 2, 15.

[14] Tol, A., Shojaeezadeh, D., Sharifirad, G., Alhani, F. and Tehrani, M.M. (2012) Determination of Empowerment Score in Type 2 Diabetes Patients and Its Related Factors. JPMA-Journal of the Pakistan Medical Association, 62, 16-20.

[15] Namakin, K., Sharifzadeh, G. and Miri, M. (2008) Prevalence of Cigarette Smoking and Evaluation of Attitude and Knowledge in Its High School Boys in Birjand, 2005. Journal of Birjand University of Medical Sciences, 15, 66-70.

[16] Karimi Mahmoud, G.F. and Heydarnia, A.R. (2009) The Effect of Health Education Based on Health Belief Model on Preventive Actions of Aids on Addict in Zarandieh. Journal of Guilan University of Medical Sciences, 18, 64-73.

[17] Rahnavard, Z., Mohammadi, M., Rajabi, F. and Zolfaghari, M. (2011) An Educational Intervention Using Health Belief Model on Smoking Preventive Behavior among Female Teenagers. Hayat, 17, 15-26.

[18] Shakerinejad, G. (Ed.) (2011) Impact of Nutrition Education on Knowledge, Attitude and Practice of Adolescent Girls about Dietary Calcium According to Health Belief Model (HBM). The 1st International \& 4th National Congress on Health Education \& Promotion, 2011, 21.

[19] Alidosti, M., Sharifirad, G.R., Golshiri, P., Azadbakht, L., Hasanzadeh, A. and Hemati, Z. (2012) An Investigation on the Effect of Gastric Cancer Education Based on Health Belief Model on Knowledge, Attitude and Nutritional Practice of Housewives. Iranian Journal of Nursing and Midwifery Research, 17, 256-262.

[20] Hajian, S., Vakilian, K., Najabadi, K.M., Hosseini, J. and Mirzaei, H.R. (2011) Effects of Education Based on the Health Belief Model on Screening Behavior in High Risk Women for Breast Cancer, Tehran, Iran. Asian Pacific Journal of Cancer Prevention, 12, 49-54.

[21] Mahmoodi, M. and Salehi, L. (2011) To Evaluate of Efficacy of Education Based on Health Belief Model on Knowledge, Attitude and Practice among Women with Low Socioeconomic Status Regarding Osteoporosis Prevention. Iranian Journal of Epidemiology, 7, 30-37.

[22] Hatefnia, E., Niknami, S., Mahmoudi, M., Ghofranipour, F. and Lamyian, M. (2010) The Effects of Health Belief Model Education on Knowledge, Attitude and Behavior of Tehran Pharmaceutical Industry Employees Regarding Breast Cancer and Mammography. Journal of Kermanshah University of Medical Sciences, 14, 42-53.

[23] Goodarzi, M., Ebrahimzadeh, I., Rabi, A., Saedipoor, B. and Jafarabadi, M.A. (2012) Impact of Distance Education via Mobile Phone Text Messaging on Knowledge, Attitude, Practice and Self Efficacy of Patients with Type 2 Diabetes Mellitus in Iran. Journal of Diabetes \& Metabolic Disorders, 11, 10. 
Scientific Research Publishing (SCIRP) is one of the largest Open Access journal publishers. It is currently publishing more than 200 open access, online, peer-reviewed journals covering a wide range of academic disciplines. SCIRP serves the worldwide academic communities and contributes to the progress and application of science with its publication.

Other selected journals from SCIRP are listed as below. Submit your manuscript to us via either submit@scirp.org or Online Submission Portal.
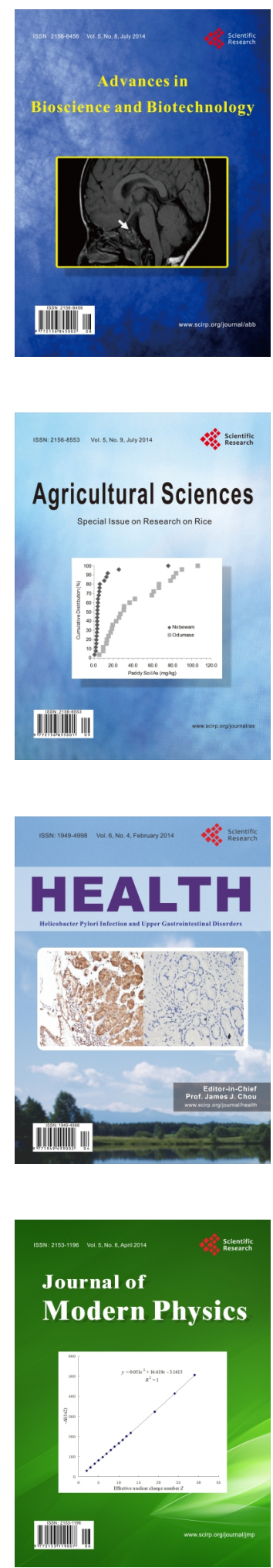
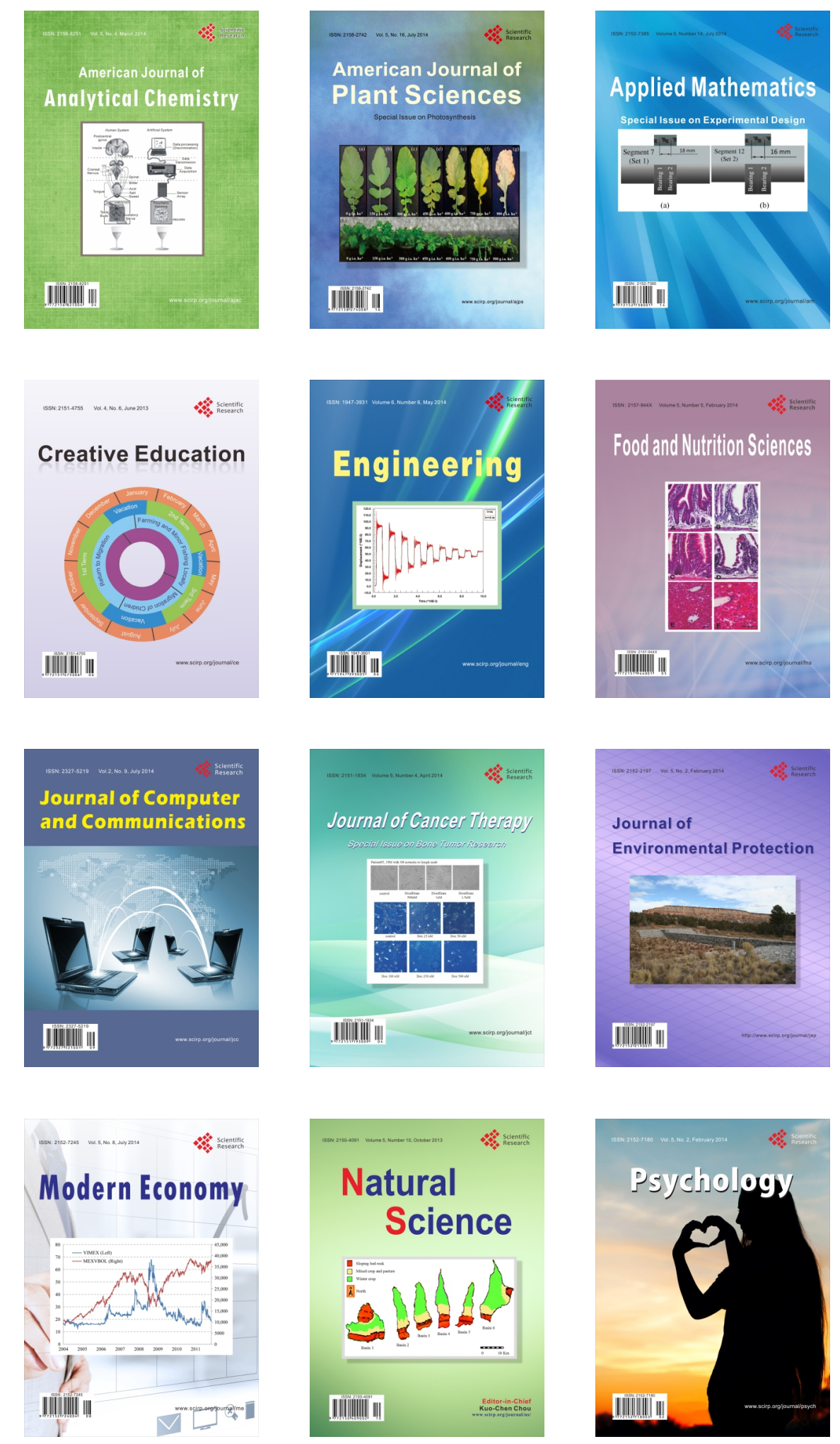